\title{
Molecular Identification of Leishmania Species Isolated From Human Cutaneous Leishmaniasis in Poledokhtar District, Lorestan Province, Iran
}

\author{
Elahe Beiranvand ${ }^{1}$, Mohsen Kalantari ${ }^{2}$, Hasan Ali Rastgar ${ }^{3,4}$, Kamyar Amraee ${ }^{5, *}$ \\ ${ }^{1}$ Department of Parasitology and Mycology, School of Medicine, Shiraz University of Medical Sciences, Shiraz, IR Iran \\ 2 Mamasani Paramedical School, Shiraz University of Medical Sciences, Shiraz, IR Iran \\ 3 Department of Medical Entomology and Vector Control, School of Public Health, Student Research Committee, Ahvaz Jundishapur University of Medical Sciences, Ahvaz, IR Iran \\ 4 Poledokhtar Health Centre, Lorestan University of Medical Sciences, Khorramabad, IR Iran \\ 5 Department of Medical Entomology and Vector Control, School of Public Health, Ahvaz Jundishapur University of Medical Sciences, Ahvaz, IR Iran \\ ${ }^{*}$ Corresponding author: Kamyar Amraee, Department of Medical Entomology and Vector Control, School of Public Health, Ahvaz Jundishapur University of Medical Sciences, Ahvaz, \\ IR Iran.Tel/Fax:+98-6113738282, E-mail: Amraee-k@ajums.ac.ir.
}

Received: September 09, 2012; Revised: March 05, 2013; Accepted: Jun 29, 2013

\begin{abstract}
Background: Cutaneous leishmaniasis with zoonotic and anthroponotic forms is an endemic disease and a health problem in our country. Identification of parasite species and the type of disease is very important for treatment of disease as well as planning the control program. This study was carried out to identify the parasite species causing cutaneous leishmaniasis by Nested PCR in Poledokhtar district, Lorestan province, Iran.

Objectives: Identification of Leishmania species on patients' leishmanial infections in Poledokhtar district, Lorestan province, Iran.

Materials and Methods: This descriptive study was performed on 52 cutaneous leishmaniasis patients who referred to Poledokhtar health centre laboratory since 2008 - 2011. DNA was extracted from slide samples by phenol-chloroform-isoamyl alcohol method, and was evaluated by specific primers of kinetoplast DNA(CSB1XR, CSB2XF, LiR and 13Z) using Nested-PCR.

Results: From 52 confirmed parasitological cases, 31 (59.62\%) were male and 21 (40.38\%) were female. The results of PCR electrophoresis indicated that 50 (96.15\%) cases were Leishmania major and 2 (3.85\%) L.tropica.

Conclusions: The results of the current study indicated that most of the recognized cases of cutaneous leishmaniasis in Poledokhtar were due to L. major. Further studies based on reservoir and vector of cutaneous leishmaniasis must be carried out in order to clarify the epidemiological aspect of leishmaniasis in Poledokhtar district.
\end{abstract}

Keywords: Leishmaniasis; Cutaneous; Leishmania major; L. tropica; Polymerase Chain ReactionPolymerase Chain Reaction

\section{Background}

Cutaneous Leishmaniasis (CL) continues to be an increasing public health problem in Iran (1). CL is endemic in half of the 30 Iranian provinces (2). Recently, several new foci have been reported, indicating the potential spread of the disease in the country (3). Both epidemiological forms of CL are present in Iran; Zoonotic Cutaneous Leishmaniasis (ZCL) caused by Leishmania major and Anthroponotic Cutaneous Leishmaniasis (ACL) due to $L$. tropica (4). Essentially, identification of Leishmania parasites is necessary for epidemiological objectives such as documenting the distribution of prevalent species and designing appropriate control measures, and it is also important for treatment modality (5-7). Leishmania parasites have similar morphology and sometimes cause similar clinical manifestations; therefore, differentiation among species requires molecular techniques such as
Polymerase Chain Reaction (PCR) (8).

So far, some different molecular techniques such as RFLP (9-11), RAPD $(5,12,13)$, Real-time PCR $(14,15)$ and Nested PCR $(1,16-19)$ have been performed regarding the identification of Leishmania in human specimen by species level. A Nested PCR based method that permits both very sensitive detection and high-resolution identification of Leishmania parasites directly from clinical samples is presented here (20). This is the first study of molecular identification of Leishmania species in Poledokhtar district, also Lorestan province.

\section{Objectives}

This cross-sectional study was conducted to identify the Leishmania spp. isolated from CL patients who referred to Poledokhtar health centre, using Nested PCR method. species causing cutaneous leishmaniasis in Poledokhtar district, Lorestan province, Iran.

Copyright (c) 2013, Ahvaz Jundishapur University of Medical Sciences; Licensee Kowsar Ltd. This is an Open Access article distributed under the terms of the Creative Commons Attribution License (http://creativecommons.org/licenses/by/3.0), which permits unrestricted use, distribution, and reproduction in any medium, provided the original work is properly cited. 


\section{Materials and Methods}

\subsection{Sampling and Study Area}

This descriptive study was performed on 52 patients infected by Leishmania and referred to Poledokhtar health centre laboratory in 2008-2011. The slide smears of lesions patients suspected to CL were prepared using Giemsa staining. Then the leishman bodies were observed using common microscopic technique and they were subjected to molecular technique to be identified. The Poledokhtar district $\left(33^{\circ} 9^{-} 13^{\prime \prime} \mathrm{N}, 47^{\circ} 42^{-} 49^{\prime \prime}\right.$ E at an altitude of about $660 \mathrm{~m}$ above sea level) lies in the south of Lorestan province. The weather is hot in the summer and moderate in the winter.

\subsection{DNA Extraction}

The smear scrapings were added to $150 \mu$ lysis buffer (50mm Tris-Hcl pH 7.6,1mm EDTA pH 8.0,1\% Tween 20, 8.5 $\mu \mathrm{l}$ proteinase $\mathrm{K}$ solution $19 \mathrm{mg} / \mathrm{mL}$ ) and incubated for 2 $\mathrm{h}$ at $55^{\circ} \mathrm{C}$. Phenol-chloroform- isoamyl alcohol extraction method was used to extract DNA. The DNA samples were dissolved in $50 \mu$ l deionized distilled water and stored at $4^{\circ} \mathrm{C}(21)$.

\subsection{Nested-PCR}

Special primers related to variable regions of kDNA were used in a Nested-PCR technique. The external primers CSB1XR (CGA GTA GCA GAA ACT CCC GTT GA) and CSB2XF (ATT TTT CGC GAT TTT CGC AGA ACG) in the first round and internal primers LiR (TCG CAG AAC GCC CCT) and $13 Z$ (ACT GGG GGT TGG TGT AAA ATA G) in the second round were applied.DNA was amplified using programmable Thermocycler (Thecne Cambridge, UK) under the following conditions: $5 \mathrm{~min}$ at $94^{\circ} \mathrm{C}$ followed by 35 cycles of $30 \mathrm{sec}$ at $94^{\circ} \mathrm{C}, 60 \mathrm{sec}$ at $55^{\circ} \mathrm{C}, 90 \mathrm{sec}$ at $72^{\circ} \mathrm{C}$ and a final elongation at $72^{\circ} \mathrm{C}$ for $10 \mathrm{~min}$.

\subsection{Agarose gel Electrophoresis}

The PCR products were visualized by $1.5 \%$ agarose gel electrophoresis (Uvitech, Cambridge UK), using a $100 \mathrm{bp}$ DNA ladder marker at $260 \mathrm{~nm}$ wavelength. A negative control and three positive controls including L. major (MHOM/IR/54/LV39), L. tropica (MHOM/IR/89/ARD2) and L. infantum (MCAN/IR/96/Lon49) were used in each round of PCR and electrophoresis. L. tropica, L. major and L. infantum provided fragments of $750 \mathrm{bp}, 560 \mathrm{bp}$ and $680 \mathrm{bp}$ respectively.

\section{Results}

From 52 confirmed parasitological cases, 59.62\% were male and $40.38 \%$ were female (Table 1 ). The results of the second-round PCR showed that L. tropica generated a 750bp fragment whereas L. major generated a 560bp (Figure 1). Comparison of the pattern of electrophoretic profile of the studied isolates with the electrophoretic pattern of reference strains helped to identify that from 52 isolates, the prevalence of L. major was 50 (96.15\%) and that of L. tropica was 2 (3.85\%) among the cases. $L$. major isolates were from some parts of Poledokhtar. The more detailed information related to the different parts of the studied area is presented in the Table 2.

Table 1. Clinical Appearance of Lesions in 52 Cases Suffering From CL

\begin{tabular}{llll}
\hline $\begin{array}{l}\text { Clinical form of the } \\
\text { lesion }\end{array}$ & Male & Female & Total, No.(\%) \\
\hline Dry & 4 & 4 & $8(15.38)$ \\
Moist & 27 & 17 & $44(84.62)$ \\
Total & 31 & 21 & $52(100)$ \\
\hline
\end{tabular}

Figure 1. Gel Electrophoresis Results of Nested-PCR of Leishmania Parasites Isolated From Patients Using the Primers CSB1XR, CSB2XF, $13 Z$ and LIR

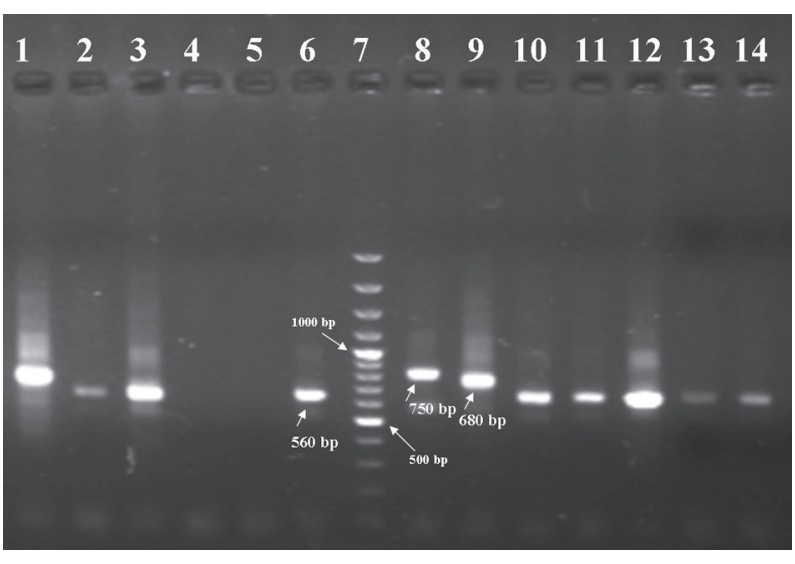

L. tropica isolated from the patient (lane 1), L. amajor isolated from the patients (lanes 2, 3, 10, 11, 12, 13 and 14), Negative controls (lanes 4 and 5), reference strain of L. major (560 bp) (lane 6), marker (100-bp ladder) (lane 7), reference strain of L. tropica (750 bp) (lane 8), reference strain of L. infantum (680 bp) (lane 9).

Table 2. Molecular Identification of Leishmania Species in Poledokhtar District by Part

\begin{tabular}{llll}
\hline Part & Cases & $\begin{array}{l}\text { L. major, } \\
\text { No. }(\%)\end{array}$ & $\begin{array}{l}\text { L.tropica } \\
\text { No. }(\%)\end{array}$ \\
\hline City Centre & 6 & $6(100)$ & - \\
\hline Mamoolan & 4 & $3(75)$ & $1(25)$ \\
\hline Afrineh & 6 & $5(83.33)$ & $1(16.67)$ \\
Malavi & 12 & $12(100)$ & - \\
\hline Jaidar & 11 & $11(100)$ & - \\
Jelogir & 4 & $4(100)$ & - \\
Western Miankouh & 8 & $8(100)$ & - \\
Eastern Miankouh & 1 & $1(100)$ & - \\
Total & 52 & $50(96.15)$ & $2(3.85)$
\end{tabular}




\section{Discussion}

Accurate identification of the Leishmania species seems to be necessary for a variety of clinical and epidemiological reasons to decide on distinct treatment regimens and also design appropriate control programmers (22). DNAbased techniques have been commonly used as potential tools for this purpose (23). The current study showed that ZCL was prevalent in Poledokhtar district. It is recommended that more studies should be carried out to identify vectors and reservoirs of L. Major in the Poledokhtar, and according to the type of parasite and its reservoirs CL control programs should be applied in this area. The obtained results of the current investigation are in consistence with the studies of Maraghi et al.(16), Razmjou et al. (1), Alimoradi et al. (12), Azizi et al. (17), Khosravi et al. (14), Rahbarian et al. (24), Mohamadi Azni et al. (18), Maraghi et al. (25), and Ghasemian et al. (26) that they had reported the frequency of L. major from $86-100 \%$.

However, the current study results were different from Hajjaran et al. (5), Sharifi et al. (19) and Mohajeri et al. (13), The results of the current study indicated that most of the recognized cases of CL in Poledokhtar were due to L. major. In conclusion, characteristics of the collected Leishmania isolates showed that L. major is predominant agents of CL, like other western and southeastern regions. Based on the studies conducted in the southwest and west of the Country in Khuzestan, Kermanshah and Ilam Provinces, L. major isolates were recovered and identified from CL patients $(12,16,27)$ and $L$. major recovered from wild rodents like Tateraindica, and Merioneslibycus as the principal reservoirs host in this area (28). Further studies on reservoir and vector of ZCL are necessary to better clarify the epidemiological aspect of leishmaniasis in Poledokhtar district.

\section{Acknowledgements}

The authors would like to appreciate the kind collaboration of Health Centre staff of Poledokhtar district and molecular parasitology laboratory staff of Shiraz University of medical sciences.

\section{Authors' Contribution}

Study concept and design: Amraee and Rastgar; Analysis and interpretation of data: Kalantari, Beiranvand and Amraee; Drafting of the manuscript: Amraee.

\section{Financial Disclosure}

None Declared.

\section{Funding/Support}

None Declared.

\section{References}

1. Razmjou S, Hejazy H, Motazedian MH, Baghaei M, Emamy M, Ka- lantary M. A new focus of zoonotic cutaneous leishmaniasis in Shiraz, Iran. Trans R Soc Trop Med Hyg. 2009;103(7):727-30.

2. Moemenbellah-Fard MD, Kalantari M, Rassi Y, Javadian E. The PCR-based detection of Leishmania major infections in Meriones libycus (Rodentia: Muridae) from southern Iran. Ann Trop Med Parasitol. 2003;97(8):811-6.

3. Oshaghi MA, Rasolian M, Shirzadi MR, Mohtarami F, Doosti S. First report on isolation of Leishmania tropica from sandflies of a classical urban Cutaneous leishmaniasis focus in southern Iran. Exp Parasitol. 2010;126(4):445-50.

4. Sharifi I, Poursmaelian S, Aflatoonian MR, Ardakani RF, Mirzaei M, Fekri AR, et al. Emergence of a new focus of anthroponotic cutaneous leishmaniasis due to Leishmania tropica in rural communities of Bam district after the earthquake, Iran. Trop Med Int Health. 2011;16(4):510-3.

5. Hajjaran H, Mohebali M, Razavi MR, Rezaei S, Kazemi B, Edrissian GH, et al. Identification of Leishmania species isolated from human cutaneous leishmaniasis, using random amplified polymorphic DNA (RAPD-PCR). Iran J Publ health. 2004;33(4).

6. Croft SL, Sundar S, Fairlamb AH. Drug resistance in leishmaniasis. Clin Microbiol Rev. 2006;19(1):111-26.

7. Alvar J, Croft S, Olliaro P. Chemotherapy in the treatment and control of leishmaniasis. Adv Parasitol. 2006:61:223-74.

8. Mahmoodi MR, Mohajery M, Tavakkol Afshari J, Taghae Shakeri M, Yazdan Panah MJ, Berenji F, et al. Molecular identification of Leishmania species causing cutaneous leishmaniasis in Mashhad, Iran. Jundishapur J Microbiol. 2011;3(4):195-200.

9. Mohammadi Azni S, Rassi Y, Oshaghi MA, Yaghoobi Ershadi MR Mohebali M, Abai MR, et al. [Identification of Leishmania parasites of patients and cutaneous leishmaniasis reservoir rodents staining slides using PCR-RFLP in Damghan district]. J Hamedan Univ Med Sci. 2011;17(4):5-9.

10. Saki J, Khademvatan S. A molecular study on cutaneous leishmaniasis lesions in Khuzestan province (South west of Iran). Jundishapur J Microbiol. 2012;4(4):283-8.

11. Akhoundi M, Hajjaran H, Baghaei A, Mohebali M. Geographical distribution of leishmania species of human cutaneous leishmaniasis in fars province, southern iran. Iran J Parasitol. 2013;8(1):85-91.

12. Alimoradi S, Hajjaran H, Mohebali M, Mansouri F. Molecular identification of Leishmania species isolated from human cutaneous leishmaniasis by RAPD-PCR. Iran J Publ health. 2009;38(2).

13. Mohajeri M, Hajjaran H, Shamsian SAA, Tavakol Afshari I, Saadabadi F. [Identification of cutaneous leishmaniasis agents by RAPD-PCR in Neishapour district]. J Mashhad Univ Med Sci. 2008;51(100):79-86.

14. Khosravi S, Hejazi SH, Hashemzadeh M, Eslami G, Darani HY Molecular diagnosis of Old World leishmaniasis: real-time PCR based on tryparedoxin peroxidase gene for the detection and identification of Leishmania spp. J Vector Borne Dis. 2012;49(1):15-

15. Khademvatan S, Neisi N, Maraghi S, Saki J. Diagnosis and identification of Leishmania spp. from Giemsa-stained slides, by realtime PCR and melting curve analysis in south-west of Iran. Ann Trop Med Parasitol. 2011;105(8):559-65.

16. Maraghi S, Zadeh AS, Sarlak AA, Ghasemian M, Vazirianzadeh B. Identification of Cutaneous Leishmaniasis Agents by Nested Polymerase Chain Reaction (Nested-PCR) in Shush City, Khuzestan Province, Iran. Iran J Parasitol. 2007;2(3).

17. Azizi K, Soltani A, Alipour H. Molecular detection of Leishmania isolated from cutaneous leishmaniasis patients in Jask County, Hormozgan Province, Southern Iran, 2008. Asian Pac J Trop Med. 2012;5(7):514-7.

18. Mohammadi Azni S, Rassi Y, Oshaghi MA, Yaghoobi Ershadi MR, Mohebali M, Abai MR, et al. [Determination of parasite species of cutaneous leishmaniasis using Nested PCR in Damghan, Iran, during 2008]. J Gorgan Univ Med Sci. 2010;13(1):59-65.

19. Sharifi F, Sharifi I, Zarean M, Parizi MH, Aflatoonian M, Harandi MF, et al. Spatial distribution and molecular identification of leishmania species from endemic foci of South-eastern iran. Iran JParasitol. 2012;7(1):45-52.

20. Noyes HA, Reyburn H, Bailey JW, Smith D. A nested-PCR-based 
schizodeme method for identifying Leishmania kinetoplast minicircle classes directly from clinical samples and its application to the study of the epidemiology of Leishmania tropica in Pakistan. J Clin Microbiol. 1998;36(10):2877-81

21. Motazedian H, Karamian M, Noyes HA, Ardehali S. DNA extraction and amplification of leishmania from archived, Giemsastained slides, for the diagnosis of cutaneous Leishmaniasis by PCR. Ann Trop Med Parasitol. 2002;96(1):31-4.

22. Grimaldi G, Jr, Tesh RB. Leishmaniases of the New World: curren concepts and implications for future research. Clin Microbiol Rev. 1993;6(3):230-50.

23. Reithinger R, Dujardin JC. Molecular diagnosis of leishmaniasis: current status and future applications. J Clin Microbiol. 2007;45(1):21-5.

24. Rahbarian N, Mesgarian A, Mahmoudi Rad M, Hajaran H, Shahbazi F, Mesgarian Z, et al. Identification of leishmania species isolated from human cutaneous leishmaniasis using PCR method.J
Res Health Sci. 2009;9(2):48-51.

25. Maraghi S, Mardanshah O, Rafiei A, Samarbafzadeh A, Vazirianzadeh B. Identification of cutaneous leishmaniasis agents in four geographical regions of Khuzestan province using Nested PCR. Jundishapur J Microbiol. 2013;6(4):In Press.

26. Ghasemian M, Maraghi S, Samarbafzadeh AR, Jelowdar A, Kalantari M. The PCR-based detection and identification of the parasites causing human cutaneous leishmaniasis in the Iranian city of Ahvaz. Ann Trop Med Parasitol. 2011;105(3):209-15.

27. Rassi Y, Jalali M, Javadian E, Motazedian MH. Confirmation of Meriones libycus (Rodentia: Gerbillidae) as the main reservoir host of zoonotic cutaneous leishmaniasis in Arsanjan, Fars province, south of Iran (1999-2000). JPubl Health. 2001;30(3-4):143-44

28. Mohebali M, Javadian E, Yaghoobi-Ershadi MR, Akhavan AA, Hajjaran $\mathrm{H}$, Abaei MR. Characterization of Leishmania infection in rodents from endemic areas of the Islamic Republic of Iran. East Mediterr Health J. 2004;10(4-5):591-9. 